\title{
O Papel Público das Religiões na Busca de uma Concepção Contra- Hegemônica de Direitos Humanos
}

Anaxsuell Fernando da Silva'

SANTOS, Boaventura de Sousa. Se Deus fosse um ativista dos Direitos Humanos. 2. ed. São Paulo: Cortez Editora, 2014. 176 p.

$\mathrm{Na}$ contramáo de alguns prognósticos da modernidade iluminista a religião não deixou de despertar o fascínio humano. E, por isso, o interesse político e acadêmico a respeito do discurso religioso segue em franco crescimento. A propósito, "para o bem e para o mal, a religião nunca abandonou o domínio público"; e é exatamente por este motivo que se debruçar academicamente a respeito do papel público e político das religióes configura-se como algo de substantiva relevância no debate sociológico contemporâneo.

A discussão em torno dos chamados direitos humanos, por sua vez, remonta à matriz do pensamento liberal no ocidente. $\mathrm{O}$ arcabouço conceitual, jurídico e de direito sob o qual se sustenta emergiu no interior de uma sociedade globalizada e, por conseguinte, orientada pelos princípios de regulação do deus-mercado. Dito de outro modo, os direitos humanos são, via de regra, discutidos no âmbito das Ciências Sociais, Políticas e Jurídicas, enquanto um desdobramento natural do pensamento liberal e das lutas políticas europeias da Modernidade, nos quais o liberalismo clássico e suas convicçóes de liberdade individual e igualdade formal são consideradas pontos nodais destes direitos.

A significativa produção bibliográfica em torno desta questão pode enganosamente sugerir-nos que ela está esgotada e, por isso, não seja digna de maiores investimentos analíticos. A rigor, um olhar mais atento perceberá a

I Doutor em Ciências Sociais pela Universidade Estadual de Campinas (Unicamp) e Professor da Universidade Federal da Integração Latino-Americana (Unila). 
prevalência de trabalhos fundamentados nas mesmas premissas incontestáveis. De acordo com tais asserções, os direitos humanos são interpretados como um projeto moral, jurídico e político criado na Modernidade Ocidental e que, após seu desenvolvimento e maturação, foi disseminado no resto do mundo.

É inegável que as últimas décadas têm presenciado um reconhecimento, simultaneamente expansivo e expressivo, de discursos a respeito da dignidade humana, da não-discriminação e da valorização da diversidade. A despeito disso, alguns desafios se impóem para a renovaçáo do aparato teórico em torno dos fundamentos dos direitos humanos. Entre estes, merece destaque, inclusive, a própria discussão sobre à genealogia conceitual dos direitos humanos, isto é, sua vinculaçáo a uma geopolítica do conhecimento.

A concepção dos direitos humanos predominantes nos debates públicos manifesta seus interesses em dois sujeitos jurídicos: o indivíduo e o Estado; preterindo coletividades, grupos marginalizados socialmente e as vítimas sistemáticas da opressão por questóes relativas à raça, gênero e etnia. É, pois, neste cenário de perplexidade que emerge uma concepçáo alternativa de luta por justiça social das minorias, uma busca contra-hegemônica e intercultural. Pois, sob este prisma, as origens dos direitos humanos teriam pouco ou nada a ver com a história e a racionalidade dos povos náo ocidentais.

Em uma sucessão de publicaçóes recentes, o sociólogo português Boaventura de Sousa Santos tem criticado a legitimaçáo dos direitos humanos no sistema internacional ${ }^{2}$. É nesta conjuntura que Se Deus fosse um ativista de Direitos Humanos, publicada pela editora Cortez, seinsere. Ainda no prefácio, o autor assinala "a fragilidade dos direitos humanos, enquanto gramática de dignidade humana e o desafio que a emergência das teologias políticas lhes coloca no início do século XXI". O livro advém desta constatação e caminha com uma intenção: a saber, cooperar para o desenvolvimento de uma "teoria de vanguarda" (2014, p. 10). E, na medida em que o faz apercebe-se da influência que as crenças religiosas ou a espiritualidade das várias religióes exerce nos ativismos e na luta por "justiça socioeconômica, histórica, sexual, racial, cultural e pós-colonial” (p. 11). As diferentes maneiras pelas quais a religião se

2 Aqui cabe evocar dois bons exemplos: primeiro a publicação do artigo: "Por uma concepção multicultural de direitos humanos"; publicado na Revista Crítica de Ciências Sociais, n. 48, jun. 1997. E, também, o liuro Direitos humanos, democracia e desenvolvimento, editado pela Cortez em 2013. 
transpassa a estas lutas constitui inspiração para as mesmas e, na perspetiva do autor, atesta que a "ideologia da autonomia e do individualismo possessivos" (p. 8), típica da Modernidade ocidental, foi posta em cheque.

Boaventura de Sousa Santos é muito conhecido no Brasil e dispensaria grandes apresentaçóes. Ele é professor catedrático da Faculdade de Economia da Universidade de Coimbra e distinguished legal scholar da Universidade de Wisconsin-Madison (EUA) e Global Legal Scholar da Universidade de Warwick. Dirige do Centro de Estudos Sociais (CES) da Universidade de Coimbra; cabe ainda relembrar que é Doutor em Sociologia do Direito pela Universidade de Yale (1973); atualmente coordena o Observatório Permanente de Justiça.

No trabalho em questáo, o autor suspende o pressuposto vigente - tanto no direito, quanto nas relações internacionais - a respeito da universalidade e generalidade dos direitos humanos e sugere tratá-los sob um novo ponto de vista. Boaventura de Sousa Santos advoga pela reconstrução emancipatória da ideia de direitos. Estes deveriam fundamentar-se na noção de dignidade humana advinda das experiências políticas de democracia participativa e de multiculturalismo. Seu método para tal empreendimento intelectual, a "hermenêutica diatópica", considera as diferentes acepçôes de dignidade humana a fim de avigorar um diálogo intercultural contra-hegemônico. Assim, no livro sob análise, publicado em 2014, se propóe a problematizar um contexto social cada vez mais recorrente na contemporaneidade: "as concepçóes da religiáo" e sua presença (menor ou maior) na vida pública. De acordo com o autor, a religião e os direitos humanos constituem "duas políticas normativas" as quais não aparentam ter nada em comum.

Uma das críticas mais antigas, retomada neste livro, no debate a respeito dos direitos humanos está no âmbito da sua propensão universalizante e genérica. Sem força heurística, o discurso em defesa da dignidade humana por grupos sociais, organizaçóes e governos tornou-se mera retórica. Estes têm amoldado, acomodado e transformado os discursos internacionais de direitos humanos às políticas hegemônicas ocidentais. E, cabe relembrar, a compreensão de mundo ultrapassa significativamente a compreensão ocidental do mundo.

Nos últimos anos diversos movimentos de resistência contra a opressão, marginalização e exclusão vieram à tona. Seus fundamentos político-ideológicos não partilham, necessariamente, as mesmas referências culturais e 
políticas dominantes no ocidente ao longo do século XX. Tais movimentos estão, amiúde, arraigados em identificações históricas e culturais multisseculares; e, por diversas vezes, isto incluí a militância religiosa. Trata-se de movimentos com conteúdopolítico diversificado, por exemplo: os movimentos indígenas na América Latina, os movimentos de camponeses na África e na Ásia e a insurgência islâmica.

Neste sentido, Boaventura afirma que o confinamento da religiáo ao espaço privado, uma vez compreendido a partir da sua distinçáo com o espaço público, é uma perspectiva do imaginário político de raiz ocidental. A despeito do iluminismo europeu, a religião não ficou circunscrita à esfera privada. Especialmente quando consideramos a ação religiosa em esfera global. De fato, a maneira com que a população europeia se relaciona com a religião é vigorosamente diferente do modo com que os norte-americanos a experimentam em seu país: nos EUA, por exemplo, a política conservadora é diretamente relacionada à fé protestante. Na América Latina, por outro lado, há uma efervescência religiosa difusa, na prática e no discurso, seja pelas diversificadas vertentes cristâs (pentecostalismos ou novos movimentos católicos) ou pelas religiôes afrolatinas. O Islá, do ponto de vista numérico é a segunda religião mundial e se constitui numa referência modelar na discussão a respeito da presença da religiáo no espaço público.

Por este motivo, os fundamentalismos estão cada vez mais palpáveis seja como experiência religiosa ou como problemática de reflexão acadêmica. $\mathrm{Na}$ obra em apreciação, o autor disserta a respeito das religióes semitas, Judaísmo, Cristianismo e Islã, e faz distinção entre teologias pluralistas e fundamentalistas. Contudo, Boaventura não aborda em seu livro apenas os fundamentalismos religiosos. Ao contrário, de maneira mais ampla - e cuidadoso para náo cair em generalidades ou análises superficiais - ele debruça nos desafios que a emergência das teologias políticas impóe aos direitos humanos nos tempos atuais.

No primeiro capítulo, globalização das teologias política, o autor faz uma abordagem conceitual dos termos hegemônico, contra-hegemônico e não-hegemônico. Pelo primeiro compreende-se a atuação social advinda da normatividade cultural dominante e fundada por relaçóes de poderes desiguais, sejam as relaçôes econômicas, sociais, políticas, culturais e epistemológicas. As relaçóes hegemônicas sustentam-se em três estruturas principais de poder e de dominação: capitalismo, colonialismo e sexismo. Por contra-hegemônico 
concebe-se uma atuação social traduzida em lutas, movimentos ou iniciativas cujo fim é converter contextos desiguais de poder em relaçóes de autoridade compartilhada, valendo-se, para tanto, dos discursos e práticas inteligíveis às várias culturas e articuladas a partir de ações coletivas.

Neste momento de sua reflexão, Santos (2014, p. 29) também nos informa sua compreensão do fenômeno da globalização, o qual por não sendo único, deve ser caracterizado nomeadamente por movimentos dialéticos: a globalização neoliberal hegemônica (a nova fase do capitalismo global) e a globalização contra-hegemônica (constituída pelos movimentos, organizaçóes sociais que lutam contra a opressáo capitalista e colonialista, contra a desigualdade e a discriminaçáo racial e sexual, entre outras). Outro conceito importante para Santos no argumento que empreenderá ao longo do livro é apresentado neste capítulo (2014, p. 35) trata-se de teologia política. Esta acepção relaciona-se às diferentes maneiras de perceber a intervençáo da religião, como mensagem divina, na organização social e política da vida social, dito de outro modo, a sanção religiosa às estruturas sociais e políticas existentes. Ainda segundo o autor, de uma maneira mais ou menos intensa, todas as teologias políticas questionam a diferenciação moderna entre público e privado e postulam a intervenção da religiáo na esfera pública.

O capítulo seguinte preocupa-se com o caso do fundamentalismo islâmico, tanto do seu legado histórico e cultural quanto da sua disposição à crítica radical endereçada ao imperialismo ocidental. Aos olhos reducionistas do ocidente, as sociedades muçulmanas são retrógradas, antidemocráticas e violentas. A diversidade no sistema de crença do Islá é desconsiderada. E, a esta percepção una reduzir-se-ia a noção de teologia política. Para o autor, no contexto do Islã fundamentalista, a luta contra as discriminaçóes de classe, sexo, raça, casta, orientação social ou opção religiosa é um tema no qual a modernidade ocidental e o Islã se apresentam ainda mais distantes. Embora a expressão fundamentalismo tenha nos dias atuais conotaçóes islamofóbicas, ela surgiu nos Estados Unidos da América para categorizar grupos cristãos.

E, por isso, no terceiro capítulo, o sociólogo português aborda o fundamentalismo cristão, procedente dos Estados Unidos e disseminado na América Latina, África e Ásia. A “Nova Direita Cristâ" busca recompor a hegemonia cultural do protestantismo evangélico, quer recristianizar a Constituição, a República e a sociedade civil. Basicamente, o ponto nodal dos grupos 
fundamentalistas está na percepção de que a sociedade moderna flexibilizou a compreensão de família, da educação e pleiteia o aborto. O objetivo é fazer com que as demandas trazidas à esfera pública por movimentos emancipatórios, tais como os de mulheres e os movimentos LGBTs, sejam devolvidas ao domínio do privado. Neste cenário de teologia política, a autoridade moral e irrefutabilidade da Bíblia deve voltar a ser considerada. O livro sagrado do cristianismo deveria ser acolhido como o legítimo princípio condutor da vida na nação.

No quarto capítulo - os direitos humanos na zona de contato das teologias políticas - o tema principal é "zonas de contato", isto é, o lugar no qual as diferentes concepçóes de ordem social se entrecruzam, convergem ou tensionam. A emergência das distintas teologias políticas produz zonas de aproximação entre distintas cosmovisóes, resultando em novas e variadas formas de turbulência política, cultural e ideológica. São espaços sociais em que discursos, universos simbólicos e formas de poder convergem em condiçóes desiguais e interagem de múltiplas formas (resistência, rejeição, assimilação etc.), de modo a dar origem às controvérsias públicas.

O quinto e penúltimo capítulo, São possiveis outros direitos humanos?Traz consigo o ponto fulcral para a argumentaçáo do autor: seria possível outras concepçóes de direitos humanos? Considerando os desafios apontados pelas distintas teologias políticas discutidas ao longo do livro, percebe-se a fragilidade discursiva acionada pelos direitos humanos nas nomeadas "zonas de contato" e desvelam a debilidade das respostas produzidas. Reconhecer o desfalecimento dos direitos humanos possibilita repensá-lo, reconstruir a partir do que existe e avançar além das possibilidades dadas. A luta por direitos humanos deve ser instrumento de resistência, mecanismo de emancipação social nos distintos contextos sociais, no quais o exercício da tradução intercultural é imprescindível. Trata-se de uma nova hermenêutica, apartada do capitalismo e seu colonialismo epistêmico. O refinamento intercultural das concepçóes de dignidade humana náo apenas deverá tonificar a legitimidade das lutas orientadas em seu nome, como também colaborará no realce das concepçóes que mais rigorosamente confrontam as dimensóes da injustiça social.

No último capítulo, o sexto - para uma concepção pós-secularista dos direitos humanos: direitos humanos contra-hegemônicos e teologias progressistas - Boaventura de Sousa Santos buscou aprimorar sua reflexão a respeito da concepção 
pós-secularista dos direitos humanos: isto é, direitos humanos contra-hegemônicos e teologias progressistas. Os direitos humanos contra-hegemônicos só podem ser concebidoscomolutas contra o sofrimento humano injusto. As últimas décadas presenciaram um fortalecimento das religióes e das teologias. Obviamente, algumas usam seus produtos divinos como promotores de um conservadorismo servil a um modelo de vida social opressor. Em contrapartida, há a emergência das teologias pluralistas e progressistas, alimentada por práticas religiosas comunitárias, para as quais Deus se revela no sofrimento humano injusto. Estar a serviço deste modelo de fé é, sobretudo, testemunhar o sofrimento e lutar contra ele. Tanto a revelação quanto a redenção/libertação têm lugar nesse mundo, como expressáo de um outro mundo possível. Para o autor, neste ponto se apresenta a possibilidade de vincular a prática religiosa a serviço de Deus, a um humanismo transmoderno concreto. No que tange às teologias políticas, elas realçam a necessidade de viabilizar ao sujeito situação de dignidade em suas condiçóes históricas e sociais concretas.

$\mathrm{Na}$ teologia da libertação latino-americana (a primeira geração de teologia política ${ }^{3}$ ), Deus está diretamente envolvido na história dos povos oprimidos e em suas lutas por libertação. O desenvolvimento desta teologia possibilitou o enfrentamento de outras formas de opressão além daquela de classes, como a discriminação contra as mulheres e as diferenciaçóes de raça. A segregação étnica e religiosa e o sofrimento humano estabelecem-se em um tema fundamental para as teologias políticas.

Nos debates recentes, a moderna diferenciação entre esfera pública e privada tem sido posta em cheque pelos movimentos sociais, sobretudo pelos movimentos feministas para os quais o espaço privado é também político. $\mathrm{Pa}$ ralelamente, por diferentes motivos, o espaço público tem encolhido, mais esferas do espaço privado se transformam em campo do político, permitindo-se ser objeto de debate e de decisóes políticas. A religiáo se destaca como catalisadora dessa expansão; as teologias políticas alimentam-se desse encolhimento.

Boaventura de Sousa Santos se notabilizou pelo extenso espectro temático de sua produção bibliográfica, ainda que estas costurem seu pensamento em torno de um fio condutor - a noção de conhecimento-emancipaçãó .

\footnotetext{
3 Para uma ulterior ampliação desta temática, cabe consultar SILVA. Anaxsuell F., Poética da existência: Rubem Alves, história de vida, tramas e narrativas. Campinas/SP. Tese (Doutoradoem Ciências Sociais) - Universidade Estadual de Campinas, 2014

4 Esta constatação está presente no texto Saudação a Boaventura de Sousa Santos escrito por na Marilena Chauí no prefácio do liuro Direitos Humanos, democracia e desenvolvimento, Cortez Editora, 2013.
} 
Estes dois aspectos estão presentes de forma privilegiada na análise da crise da modernidade (SANTOS, 2009) e na construçáo de um novo paradigma para o enfrentamento e superação da crise (SANTOS, 2007). Da análise feita por Boaventura do projeto de modernidade em vigor, cabe rememorar, neste caso, sua percepção do Direito e das Ciências como componentes que viabilizam a hegemonia da regulaçáo em oposição a emancipação das formas de pensar, ser e saber.

Esta incapacidade de pensar o presente e de se projetar para o futuro seria aquilo que o autor chama de razão indolente. Alternativamente, em perspectiva contra-hegemônica, poder-se-ia buscar uma razão operante quetensiona as relaçóes constituídas a partir da/na distribuição desigual de poder. A substituição de um modelo de razão por outro implicaria, obviamente, uma transição paradigmática. E, neste cenário, seria preciso conceber uma ferramenta teórico-metodológico o qual oportunize reflexionar esta transiçáo; tal instrumental é definido pelo autor como a Sociologia das ausências e a Sociologia das emergências.

Neste bojo conceitual, em suas análises mais antigas, Boaventura pormenorizou comoaglobalização contra-hegemônica colocava-se em conflito com a globalização hegemônica, para a partir disto pleitear a renovação dos Direitos Humanos. Visto que apenas por aquele viés seria possível operar como uma política emancipatória que efetiva diálogos interculturais sob diferentes concepçôes da dignidade humana. Finalmente, em se Deus fosse um ativista dos direitos humanos? O autor postula que a ecologia dos saberes - este novo campo teórico-prático, assentado na pluralidade de conhecimento e saberes é a única estratégia epistêmica capaz de conceber um novo modelo de Direitos Humanos devido suas características nodais de autonomia e articulação. Com este argumento conclusivo, o sociólogo português, logo após retomar as várias distinçóes feitas ao longo do texto entre as diversas teologias políticas e entre os discursos e as práticas contrastantes nos direitos humanos finaliza o livro sob apreciação. E, por fim, apela que as teologias pluralistas e progressistas possam funcionar como matriz energética das lutas contra-hegemônicas e, por conseguinte, assumam a tarefa de recriar os direitos humanos.

A respeito do título intrigante e provocativo, se Deus fosse um ativista dos direitos humanos?, Boaventura de Sousa Santos assevera já nas últimas linhas que: Ele ou Ela estaria indubitavelmente à procura de uma concepção contra-hegemônica dos direitos humanos e de uma prática coerente a esta 
concepção. Em outras palavras, Ela ou Ele chegariam à conclusão de que "o Deus dos subalternos náo pode deixar de ser um Deus-subalterno" (2014, p. 155). Nesta direção, na perspectiva do autor, abrir-se-ia uma concepçáo politeísta de Deus - no seu posto de vista, a única que "permite uma resposta inequívoca a esta questáo crucial: de que lado estás? ”(p. 166).

Trata-se de uma publicação importante para fomentar o escasso debate em torno de leituras políticas da religiáo e, especialmente, das suas vinculaçóes, articulaçóes e desarticulaçóes com os direitos humanos. Outro aspecto merecedor de destaque neste livro é a sua particularidade de conter elementos os quais permitem revisitar vários construtos teóricos do autor dispersos ao longo da sua obra. Um livro que deve ser lido.

\section{Referências}

CHAUÍ, M. Saudação a Boaventura de Sousa Santos. In: Direitos humanos, democracia e desenvolvimento. São Paulo: Cortez Editora, 2013.

SANTOS, B. S. 2014. Por uma concepção multicultural de direitos humanos. Revista crítica de ciências sociais, n. 48, jun. 1997.

Se Deus fosse um ativista dos direitos humanos. 2. ed. São Paulo, Editora Cortez, 2014. 174 p.

Para além do pensamento abissal: das linhas globais a uma ecologia de saberes. Revista crítica de ciências sociais, Coimbra, n. 78, p. 3-46, 2007.

A crítica da razão indolente: contra o desperdício da experiência. 7. ed. São Paulo: Cortez, 2009.

. Direitos humanos, democracia e desenvolvimento. São Paulo: Cortez Editora, 2013.

A gramática do tempo: para uma nova cultura política. São Paulo: Cortez, 2006.

SILVA, A. F. Poética da existência: Rubem Alves, história de vida, tramas e narrativas. Tese (Doutorado em Ciências Sociais) - Universidade Estadual de Campinas, Campinas/SP, 2014.

Recebido em 20/02/2016

Aceito em 10/11/2016 